\title{
A propriedade intelectual na Alemanha: da Convenção de Berna ao Acordo de Trips
}

\author{
Intellectual property in Germany: From the Berne Convention to \\ the Trips Agreement
}

\author{
Guilherme Aparecido da Silva Maia ${ }^{1}$ \\ Rosemary Matias ${ }^{2}$ \\ Ademir Kleber Morbeck de Oliveira ${ }^{3}$
}

\begin{abstract}
RESUMO:
A Alemanha é uma das fontes dos direitos de propriedade intelectual. Desde o século XIX, essa modalidade de proteção do conhecimento vem se consolidando, desde a Convenção de Berna, em 1886, até os dias atuais. Essa configuração de direitos possibilitou a consolidação de conhecimento doméstico que alavancou a Alemanha a uma das principais potências econômicas mundiais. Deste modo, se objetivou compreender a estrutura de proteção do conhecimento da Alemanha e sua influência no desenvolvimento econômico do país. A metodologia aplicada foi a revisão sistemática, que ocorreu em três estágios: planejamento, condução e disseminação. Os resultados alcançados permitiram a compreensão da origem da propriedade intelectual e sua diferenciação dos direitos de autor; o mapeamento das instâncias jurídicas de proteção da propriedade intelectual; a identificação dos indicadores de patentes em âmbito da World Intellectual Property Organization (WIPO), 2007 a 2016; e, a comparação desses indicadores com a Holanda e Estados Unidos da América, duas potências mundiais, que lideram o spillover do conhecimento. Ao final, chega-se à conclusão de que a Alemanha consolidou sua liderança em spillover de conhecimento graças à sua estratégia de privilegiar o conhecimento doméstico. No período disponibilizado pela WIPO, apresentou ampliação constante de avanço de sua expansão de conhecimento, como também crescimento do número de patentes e do Produto Interno Bruto, com comportamento similar encontrado em outras duas potências, Holanda e Estados Unidos.
\end{abstract}

\footnotetext{
${ }^{1}$ Docente dos Cursos de Direito da Estácio de Sá e da Unigran Capital, em Campo Grande, Mato Grosso do Sul. Graduado em Direito, especialista em Inovação e Difusão de Tecnologias, mestre e doutor em Meio Ambiente e Desenvolvimento Regional, na linha de pesquisa sobre Proteção Jurídica do Conhecimento (Propriedade Intelectual e Direitos de Autor). Docente e Tutor em Educação a Distância (desde 2008).

${ }^{2}$ Graduação em Licenciatura Plena em Química pela Universidade Federal de Mato Grosso do Sul (1988). Mestrado (1995) e Doutorado (2010) em Química pela Universidade Estadual de Maringá - UEM. Professor adjunto I da Universidade Uniderp. Experiência na área de Produtos Naturais.

3 Graduação em Ciências Biológicas pela Universidade Federal de Mato Grosso do Sul (1989), Mestrado em Ecologia e Recursos Naturais pela Universidade Federal de São Carlos (1993) e Doutorado em Ciências, área de concentração em Ecologia e Recursos Naturais pela Universidade Federal de São Carlos (1996). Professor da Universidade Anhanguera-Uniderp. Tem experiência na área de Ecologia, com ênfase em Ecologia de Ecossistemas, atuando principalmente nos seguintes temas: ecologia de ecossistemas, Pantanal, etnobiologia, sementes e análise de crescimento de espécies nativas.
} 


\title{
PALAVRAS-CHAVE:
}

Sistema de proteção alemão; spillover de conhecimento; patente alemã.

\begin{abstract}
:
Germany is one of the sources of intellectual property rights. Since the nineteenth century, this modality of protection has been consolidating, from the Berne Convention in 1886 to the present day. This configuration of rights made it possible to consolidate its knowledge of Germany as one of the world's major economic powers. In this way, this article, in line with the research was built on the knowledge structure of society and its influence on the country's economic development. The methodology used is a systematic review, which occurred in three types: planning, conduction and dissemination. The results were achieved in 1995; the mapping of German legal systems for the protection of intellectual jproperty; the identification of patent indicators in the framework of the World Intellectual Property Organization (WIPO), from 2007 to 2016, and an indicator of indicators for the Netherlands and the United States of America, two world powers, leading the knowledge spillover. In the end, it came to the conclusion that Germany consolidated its leadership in knowledge overflow with its strategy of giving priority to domestic knowledge. In the period made available by WIPO, from 2007 to 2016, expansion of knowledge of knowledge expansion, as well as the growth of the number of patents and the progress of the Gross Domestic Product. The same behavior was found in two other world powers, the Netherlands and the United States.
\end{abstract}

\section{KEYWORDS:}

German protection system, knowledge spillover, german patent.

\section{INTRODUÇÃO}

$\mathrm{Na}$ Alemanha, os direitos de propriedade intelectual foram consolidados, principalmente, sobre as patentes domésticas. Este país, atualmente tão industrializado, construiu seus direitos de propriedade intelectual fundamentados na ideologia humanista, o que o foi o seu diferencial ao abordar essa temática.

Se por um lado, os países desenvolvidos como o Reino Unido e os Estados Unidos da América, situaram os direitos de propriedade no campo dos direitos utilitários, a Alemanha aderiu à ideologia humanitária e o situou no campo dos direitos fundamentais, da Constituição Federal alemã. Coube, também, tecer a teia de proteção dos direitos de autor, pois foi ela o 
berço dos debates ao entorno desses direitos, na Convenção de Berna, culminada, em 1886. Mas, afinal, como um país tão industrializado conseguiu construir um direito tão humanizado em relação à propriedade intelectual?

Esta é a questão norteadora deste trabalho, cujo objetivo é investigar como a Alemanha estruturou seus direitos de propriedade intelectual e como essa estrutura influenciou o seu desenvolvimento econômico.

Nesse contexto, foi um desafio compreender qual seria o núcleo jurídico a ser protegido pelos direitos de propriedade intelectual nesse país. Investigando-se, constatou-se que a preocupação sempre foi o vínculo entre autor e obra. Para os alemães, e, posteriormente, para o mundo jurídico, proteger o esforço (junção de tempo, dinheiro e trabalho), é o núcleo jurídico a ser protegido pela propriedade intelectual.

Para melhor compreensão do tema abordado a sequência de estudos foi dividida em: fundamentar a propriedade intelectual e os direitos de autor; compreender a consolidação da proteção do conhecimento na visão alemã; identificar e compreender o Sistema Jurídico da Propriedade Intelectual da Alemanha; e, relacionar a propriedade intelectual como fator de desenvolvimento.

\section{MATERIAL E MÉTODOS}

A metodologia aplicada para este trabalho foi a revisão sistemática, que ocorreu em três estágios: planejamento, condução e disseminação, conforme Tranfield et al. (2003), adaptado de Clark e Oxman (2001).

$\mathrm{Na}$ etapa 1, planejamento, foram identificadas as necessidades do estudo e desenvolvimento de protocolo, que foi desenvolvido a partir das seguintes questões norteadoras: Como surgiram os direitos de autor e propriedade intelectual? Como os alemães 
compreendem a propriedade intelectual e os direitos de autor? Qual a contribuição dos direitos de propriedade intelectual na consolidação da economia alemã?

Nessa etapa a estratégia de busca foi adaptada de Silva (2016) (Quadro 1).

Na etapa 2, condução, foram prospectadas, identificados, selecionados e executadas as buscas, objeto da revisão sistemática. Na estratégia de busca, itens 1, 2 e 3, as palavras-chave foram na Língua Portuguesa e direcionadas às publicações nacionais e, nas buscas 4, 5 e 6, em Inglês.

Quadro 1. Estratégia de busca das publicações com foco em propriedade intelectual e direitos de autor

\begin{tabular}{|c|l|}
\hline Estratégias de Busca & \multicolumn{1}{|c|}{ Palavras-chave e combinação de termos } \\
\hline Busca 01 & Proteção do conhecimento e propriedade intelectual \\
\hline Busca 02 & Convenções internacionais e propriedade intelectual \\
\hline Busca 03 & Direitos de autor e propriedade intelectual \\
\hline Busca 04 & Copyrights and Propriety Intellectual \\
\hline Busca 05 & Propriety Intellectual in Germany \\
\hline Busca 06 & Propriety Intellectual in Germany and Europe \\
\hline Busca 07 & Copyrights and Propriety Intellectual in Germany \\
\hline
\end{tabular}

Fonte: Adaptado de Silva (2016).

A partir da definição das palavras-chave, foi possível identificar as obras referenciadas nas publicações da Universidade de Harvard, Universidade de São Paulo e Universidade Federal do Rio Grande do Sul. Foram ainda identificadas publicações da World Intellectual Property Organization (WIPO), com critério de seleção das publicações sendo o de relevância e publicação em inglês.

Na etapa 3, disseminação, as obras foram divididas em grupos temáticos afins (assunto e localização geográfica) e identificadas as contribuições de cada autor de acordo com o campo pesquisado. 
O trabalho de busca de publicações resultou nas obras que embasam este trabalho, listadas ao final (Referências Bibliográficas).

\section{RESULTADOS E DISCUSSÃO}

\section{Os fundamentos da propriedade intelectual e dos direitos de autor na Alemanha}

Na Alemanha, a propriedade intelectual está linkada à liberdade de opinião, de arte e ciência, prevista no artigo $5, \mathrm{n}^{\mathrm{o}} 3$ do texto constitucional daquele país, in verbis: “Art. $5, \ldots$ (3) Kunst und Wissenschaft, Forschung und Lehre sind frei. Die Freiheit der Lehre entbindet nicht von der Treue zur Verfassung, significando que a arte e a ciência, a pesquisa e o ensino são livres. A liberdade de ensino não dispensa da fidelidade à Constituição (DEUTSCHLAND, 1949).

Segundo Kur e Dreier (2012), pode-se dizer que existem raciocínios idealistas para a concessão de direitos de propriedade intelectual, o que se concretiza na Alemanha, diferentemente das justificativas utilitárias que norteiam o Sistema Jurídico de Proteção do Conhecimento americano. Os fundamentos idealistas (ou não utilitários) dos direitos de propriedade intelectual, geralmente enfatizam o vínculo entre o criador e sua criação intelectual como motivo para a concessão de direitos de propriedade intelectual. As teorias utilitárias se concentram nos efeitos que o uso desses direitos tem para a sociedade, como a inovação, concorrência e satisfação do consumidor.

É claro que, na maioria das jurisdições (países ou continentes), essas duas visões acabam se sobrepondo e se moldando às necessidades e estratégias de desenvolvimento de cada uma dessas jurisdições. Interessante observar que dessas adaptações emergem duas características distintas e igualmente interessantes.

Em geral, os países acabam, naturalmente, separando a proteção do conhecimento em dois grupos distintos de direitos (os idealistas, para regular direitos autorais em relação às 
criações da literatura, da arte e das ciências e, os utilitários, assim denominados aqueles ligados à propriedade industrial, neles incluídos as patentes e as marcas). Na maioria dos países da Europa continental (em particular a França, Alemanha, Itália, Espanha e todos os outros países que, na época colonial, baseavam o seu sistema nas leis de um desses estados), os direitos dos autores se baseiam largamente na teoria idealista, já o raciocínio para os direitos autorais angloamericanos (Reino Unido, EUA e todos os outros países que basearam seu sistema nas leis de um desses estados), é utilitário. Esta diferença em relação à lógica da proteção tem seus efeitos em todos os aspectos da proteção legal (KUR e DREIER, 2012).

Com isto percebe-se que, a visão de propriedade intelectual alemã é mais idealista (humanista) do que econômica (utilitária). Para compreender como um tema tão ligado à economia foi normatizado no direito alemão, sem comprometer sua vocação idealista, foi usado como base a obra de Hoffmann e Richter (2008). Os autores, em sua obra Geistiges Eigentum in der Betriebspraxis: Erlangung, Verwaltung, Verteidigung und Verwertung von Patenten, Marken, Designs und Copyrights im Unternehmen (Propriedade intelectual na prática comercial: Aquisição, administração, defesa e exploração de patentes, marcas registradas, Projetos e direitos autorais na empresa) oferecem uma visão geral do Sistema Legal de Propriedade Intelectual. Entretanto, os autores iniciam a obra esclarecendo que o Sistema alemão de propriedade intelectual, à primeira vista, é abstrato e confuso, como dificilmente uma outra área do direito poderia ser. Segundo eles, as nomenclaturas, patente, marca registrada ou autoria muitas vezes são tratados equivocadamente como sinônimos, o que dificulta o intérprete da lei em sua aplicabilidade na prática.

Muito interessante essa informação, pois, geralmente no Brasil tende-se a acreditar que os países desenvolvidos têm normas mais elaboradas na proteção de seus interesses.

Hoffmann e Richter (2008) demonstram, com muita propriedade, a consciência da sociedade e do governo alemão em proteger o que eles classificam de valores espirituais milenares, necessidade esta fundada na consciência nacional de que a propriedade intelectual na contemporaneidade, passa transversalmente por todas as áreas da sociedade, estejam elas situadas na espera pública ou privada, econômica ou não. Segundo os autores, a propriedade intelectual está onipresente na sociedade contemporânea. Interessante a utilização deste termo, geralmente tão ligado às questões divinas nas sociedades latino americanas. 
No direito alemão, a propriedade intelectual compõe os chamados ativos suaves ou ativos não físicos da empresa. Ainda, trata-se de ativos intangíveis derivados de serviços criativos. A partir deste entendimento conceitual, há uma divisão da propriedade intelectual em três áreas distintas: os direitos de propriedade industrial, os direitos autorais e, o direito de concorrência (este, no caso, só pode ser aplicado no caso de direitos relativos à propriedade industrial). A propriedade intelectual, portanto, é um monopólio, funcionando como uma barreira de muitos obstáculos à concorrência e limite ao público em geral, conforme entendimento de Hoffmann e Richter (2008) (Figura 1).

A palavra barreira representa bem o sentido da propriedade intelectual. Por meio dela, as empresas protegem o seu patrimônio intangível, derivado dos esforços criativos de seus proprietários e colaboradores (segundo círculo, Figura 1). Por outro lado, os concorrentes, por não terem acesso a todo esse conjunto de conhecimentos, acabam perdendo espaço no mercado.

Consequentemente, a sociedade em geral (terceiro círculo, Figura 1), passa a condição de dependente dessas empresas, como é o caso sementes geneticamente modificadas patenteadas pela multinacional Monsanto, do ramo da agricultura e biotecnoloigia.
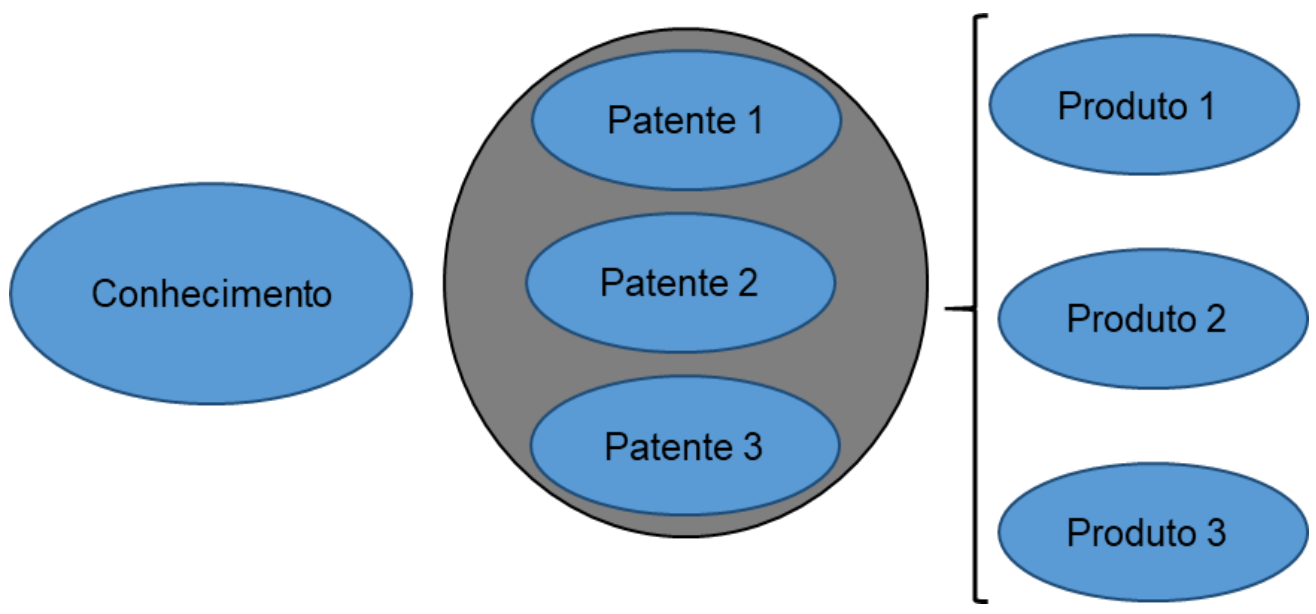

Figura 1. As barreiras do monopólio industrial proporcionado pela propriedade intelectual.

Fonte: Adaptado de Hoffmann e Richter (2008).

Deste modo, constata-se que a propriedade intelectual significa todos os direitos exclusivos em relação à propriedade intangível concedidos pelo Estado. 
A partir dessa definição, os desdobramentos dos direitos de propriedade intelectual vão, paulatinamente, se assemelhando ao entendimento dos americanos em relação ao tema, como apontado por Buskop (2008).

Assim como nos EUA, na Alemanha também há o entendimento de que, em se tratando de proteção do conhecimento, os ativos intangíveis passam a ser tratados como se tangíveis fossem. A atribuição da proteção contra terceiros, no direito alemão, leva em consideração não o objeto material em si, mas sim, a conquista espiritual nele incorporada. Nas palavras de Hoffmann e Richter (2008), não é a invenção, mas a solução técnica que está nela que deve ser protegida. Não é o romance como um produto impresso, mas sim, as palavras escolhidas e a criação individual nele contido que estão protegidos pelos direitos autorais.

\section{O desafio da proteção do conhecimento na visão alemã e as suas lições para o Brasil}

A intangibilidade é uma característica que dificulta a proteção do conhecimento. $\mathrm{O}$ desafio inicial é, primeiramente, definir a propriedade intelectual no contexto da totalidade de todos os ativos não físicos que podem ser registrados economicamente. Sendo assim, procurouse partir de um ponto de entendimento como o Sistema Legal de Propriedade Intelectual. Nesse contexto, a questão norteadora é: onde se situa a propriedade intelectual no direito alemão? Como já visto, sob o termo genérico de Direitos de Propriedade Intelectual estão contidas três subáreas: direitos de propriedade industrial (i), direitos autorais (ii) e, direitos individuais de concorrência (iii). Mas, como esses direitos se desdobram no ordenamento jurídico alemão?

Os direitos de propriedade industrial (i) protegem a patente, o modelo de utilidade, a marca registrada, o design, a variedade de cultivares e, os semicondutores. Nota-se, portanto, uma semelhança entre o direito alemão e o brasileiro em relação à proteção do conhecimento. Na Lei de Propriedade Industrial (Lei n ${ }^{\circ}$ 9.279/1996), estão garantidos os seguintes direitos de propriedade industrial: de patentes, modelo de utilidade, desenhos industriais, marcas, e, de indicações geográficas e cultivares (BRASIL, 1996). Diante disso, observar-se que a diferença está na proteção de direitos relativos à semicondutores, previsto no direito alemão e não previsto 
na lei brasileira; e, na proteção por indicações geográficas, prevista somente na lei brasileira. Nas demais áreas de proteção, ambos os países adotaram a mesma estrutura jurídico.

Em relação aos direitos de autor (ii), o legislador alemão seguiu o acordo multilateral sobre a proteção transfronteiriça da propriedade intelectual, da Convenção de Berna (WIPO, 2017). No entanto, o enfoque foi mais comercial do que artístico propriamente dito. O foco foi proteger: obras de literatura, ciência e arte, por exemplo, "composições, pinturas, esculturas, textos, produções teatrais, fotografias, filmes, transmissões de rádio, gravações de música e som" (HOFFMAN e RICHTER, 2008, p. 21). Entretanto, também oferece proteção para a exploração comercial da criação musical. Além disso, certamente possui interfaces para o escopo de proteção para inovações técnicas, como desenhos técnicos e desenvolvimento de software, entendimento sinérgico ao do legislador brasileiro.

No Brasil, o artigo $7^{\circ}$, inciso XII, da Lei de Direitos Autorais (Lei $\mathrm{n}^{\circ}$ 9.610/98), também incluiu o programa de computador em seu rol de proteção (BRASIL, 2004). Além dessa, para o programa de computador foi criada uma lei específica, a Lei de Software (Lei 9.609/98), que dispõe sobre a propriedade intelectual e comercialização de programa de computador (BRASIL, 1998). Basicamente, a Lei de Software acatou todos os direitos de propriedade intelectual abarcados pela Lei de Direitos Autorais, menos os direitos morais.

No artigo $2^{\circ}$, caput, da Lei de Software, está estabelecido que "O regime de proteção à propriedade intelectual de programa de computador é o conferido às obras literárias pela legislação de direitos autorais e conexos vigentes no País, observado o disposto nesta Lei”. Até aqui, nenhuma inconsistência, até mesmo porque é entendimento que a criação de um software de computador é uma criação do espírito, ou, comercialmente falando, um ativo intangível. Porém, no $§ 1^{0}$ do mesmo artigo, o legislador colocou o seguinte dispositivo:

“\$ $\mathbf{1}^{\circ}$ Não se aplicam ao programa de computador as disposições relativas aos direitos morais, ressalvado, a qualquer tempo, o direito do autor de reivindicar a paternidade do programa de computador e o direito do autor de opor-se a alterações não-autorizadas, quando estas impliquem deformação, mutilação ou outra modificação do programa de computador, que prejudiquem a sua honra ou a sua reputação" (BRASIL, 2004).

É entendimento que houve uma contradição do legislador, pois, se no caput do artigo $2^{\circ}$ fica claro que a proteção dada aos programas de computador é a mesma da Lei de Direitos 
Autorais, em seguida, no $\S 1^{\circ}$ ele retira a proteção moral do proprietário da obra. Os direitos morais do autor estão previstos no artigo 24, da Lei de Direitos autorais, in verbis:

\begin{abstract}
"Art. 24. São direitos morais do autor: I - o de reivindicar, a qualquer tempo, a autoria da obra; II - o de ter seu nome, pseudônimo ou sinal convencional indicado ou anunciado, como sendo o do autor, na utilização de sua obra; III - o de conservar a obra inédita; IV - o de assegurar a integridade da obra, opondo-se a quaisquer modificações ou à prática de atos que, de qualquer forma, possam prejudicá-la ou atingi-lo, como autor, em sua reputação ou honra" (BRASIL, 1998).
\end{abstract}

É de fácil compreensão a dificuldade em positivar uma norma que regulamenta e quantifica o quanto a honra de um autor foi atingida pela modificação de um programa de computador, visto ser a honra um atributo da personalidade e da moral do indivíduo. Nas palavras de Diniz (2002) apud Gabliano e Pamplona Filho (2014):

\begin{abstract}
"São direitos subjetivos da pessoa de defender o que lhe é próprio, ou seja, a sua integridade física (vida, alimentos, próprio corpo vivo ou morto, corpo alheio, vivo ou morto, partes separadas do corpo vivo ou morto); a sua integridade intelectual (liberdade de pensamento, autoria científica, artística e literária) e sua integridade moral (honra, recato, segredo pessoal, profissional e doméstico, imagem, identidade pessoal, familiar e social" (GAGLIANO e PAMPLONA FILHO, p. 234).
\end{abstract}

Nas palavras lapidadas de Cavalieri Filho (2015, p. 89):

“... O dano moral está necessariamente vinculado a alguma reação psíquica da vítima. Pode haver ofensa à dignidade da pessoa humana sem dor, vexame, sofrimento, assim como pode haver dor, vexame e sofrimento sem violação da dignidade. Dor, vexame, sofrimento e humilhação podem ser consequências, e não causas. Assim como a febre é um efeito de uma agressão orgânica, a reação psíquica da vítima só pode ser considerada dano moral quando tiver por causa uma agressão à sua dignidade ...".

É de fundamental importância esclarecer que a inviolabilidade da honra está prevista na Constituição Federal de 1988, no Título II, dos Direitos e Garantias Fundamentais, Seção I, que trata dos Direitos e Deveres Individuais e Coletivos, especificamente, no artigo $5^{\circ}$, inciso $\mathrm{X}$, nos seguintes termos: "X - são invioláveis a intimidade, a vida privada, a honra e a imagem das pessoas, assegurado o direito a indenização pelo dano material ou moral decorrente de sua violação" (BRASIL, 2016a, p. 9). Vale lembrar que os direitos fundamentais são irrenunciáveis, portanto, o legislador deveria reformar a Lei de Software para contemplar os direitos morais no âmbito da sua proteção.

Amparado no entendimento de Venosa (2011), de que “... não é porque o dano exclusivamente moral é difícil de ser avaliado economicamente que deve ser deixado de lado 
...”. Caso assim o fosse, o legislador não o teria deixado de lado, motivo pelo qual o Código Civil de 2002, em seu artigo 186 estabelece que "Aquele que por ação ou omissão voluntária, negligência ou imprudência, violar direito e causar dano a outrem, ainda que exclusivamente moral, comete ato ilícito" (BRASIL, 2016b, p. 58).

Após essa breve explanação sobre a positivação dos direitos de autor no Brasil, devese continuar a abordagem os direitos individuais de concorrência (iii).

Para compreender-se os direitos individuais de concorrência, primeiramente, é necessário compreender o papel da concorrência. Para os alemães, o núcleo jurídico a ser protegido é o que eles denominam de Lauterkeit des Verhaltens im Markt ou, Solidez do Comportamento no Mercado. Para eles, o direito de concorrência existe para manter o equilíbrio no comportamento entre empresários, na relação mercado-consumidor. Lá também existe a preocupação em evitar monopólios. Por essa razão, o governo ançou sua Kartellrecht ou, Lei Antitruste, cujo objetivo é unificar a competição de desempenho livre, porém, preservando a estabilidade econômica do país (HOFFMAN e RICHTER, 2008).

No Brasil, a primeira lei antitruste (Lei $\mathrm{n}^{\circ}$ 8.884) data de 11 de junho de 1994 e foi promulgada no governo do então presidente Itamar Franco. Ela transformou o Conselho Administrativo de Defesa Econômica (CADE) em autarquia, e criou normas para prevenir e reprimir as infrações contra a ordem econômica (BRASIL, 1994). Posteriormente, em 30 de novembro de 2011, sob o comando de Dilma Rousseff, foi promulgada a Lei no 12.529 (novo marco legal antitruste), que revogou a lei anterior e instituiu novos mecanismos de controle da concorrência (BRASIL, 2011).

No entendimento alemão, o bem a ser protegido pelo direito de concorrência é a concorrência em si. Basicamente a sua Kartellrecht não resulta em direitos especiais de proteção, mas, da proibição de se comportar de forma tal, que, o resultado desse comportamento seja o desequilíbrio. Deste modo, a função da Lei Antitruste não é inibir um direito exclusivo, mas, evitar a injustiça da concorrência desleal. Na visão dos autores, atualmente, o direito da concorrência é muitas vezes entendido como o "direito de passagem" dos direitos de propriedade industrial (HOFFMAN e RICHTER, 2008). 


\section{4. $\mathrm{O}$ direito à propriedade intelectual no sistema jurídico da Alemanha}

A questão norteadora deste tópico é: a propriedade intelectual tem status constitucional no direito alemão?

Na Alemanha, o Bundesverfassungsgericht ou, Tribunal Constitucional Federal, é um órgão independente na estrutura judiciária. Formado por dois senadores, cada um com oito juízes, ele é o guardião da Constituição Federal e para garantir os direitos fundamentais dos cidadãos alemães. Segundo esse Tribunal, a "propriedade são todos os direitos do direito simples que são de um bem" (HOFFMAN e RICHTER, 2008, p. 23).

O entendimento é o seguinte: os direitos imateriais, como o direito da patente, a marca registrada e a lei de design ou os direitos autorais são cobertos pelo regime de proteção constitucional, desde que tenham um ativo, e, como já visto anteriormente, os ativos podem ser tangíveis e intangíveis. Logo, os direitos de propriedade intelectual têm sim status constitucional no direito alemão. Entretanto, isso não implica obrigações por parte do Estado em conceder ou criar direitos de propriedade intelectual, como acontece em relação aos direitos fundamentais. Embora o Estado tenha decidido oferecer oportunidades de proteção de bens intangíveis, por meio de mecanismos de barreiras devidamente positivadas, na esfera constitucional ele apenas cristalizou o assunto como área central, obviamente como questão de soberania e estratégia de desenvolvimento da nação (HOFFMAN e RICHTER, 2008).

Segundo WIPO (2018), a primeira lei de patentes da Alemanha foi promulgada em 5 de maio de 1936 e tratava de patentes, modelos de utilidade, segredos industriais e, variedades vegetais. No entanto, em 1995, ela foi modificada por conta de notificação da Organização Mundial do Comércio (OMC) à Alemanha, para adequação ao artigo 63.2 do Acordo sobre Aspectos dos Direitos de Propriedade Intelectual Relacionados ao Comércio (TRIPS).

Além do TRIPS, a Alemanha ainda é signatária da European Convention Patent (EPC), um acordo firmado em Munique, em 1973 e que permanece em vigor até os dias atuais. Ele regula a chamada patente europeia. Para obter essa modalidade de patente, o empreendedor precisa se registrar no European Patent Office (EPO), em Munique, que realiza um procedimento independente de concessão de patentes europeias. A base para isso é a EPC. Uma 
patente europeia pode atualmente chegar a até 34 países signatários. No entanto, a proteção não é uniforme para todos os países signatários. Após a concessão, a patente europeia é dividida em direitos de propriedade nacionais individuais. Estes surgem com a publicação da patente nos respectivos países membros da EPC. O próprio empreendedor decide em que países-membros sua patente deve ser aplicada. Nesse processo, qualquer cidadão pode opor-se à concessão de uma patente europeia. Essa oposição deve ser protocolada no Instituto Europeu de Patentes no prazo de nove meses após o anúncio da sua concessão. As patentes concedidas com efeito à República Federal da Alemanha também podem ser impugnadas através de um recurso de anulação perante o Tribunal Federal de Patentes (HOFFMAN e RICHTER, 2008).

A segunda opção processual transnacional para obtenção de patentes na Alemanha, além do procedimento da EPC, é uma solicitação internacional sob o chamado Patent Cooperation Treaty (PCT). O PCT é um conjunto de vários processos, mas, ao contrário do procedimento do EPC, este grupo de processos não é examinado e concedido uniformemente a todos os países signatários, mas divide-se em procedimentos nacionais e internacionais. Os procedimentos nacionais individuais culminam com os direitos nacionais de propriedade intelectual; por outro lado, os procedimentos internacionais resultam em direitos de propriedade intelectual junto aos demais países signatários do PCT.

Os direitos de proteção desejados são tratados de acordo com a legislação nacional. O PCT atualmente tem 141 partes que podem ser "designadas" por uma patente por pedido internacional. Para este propósito, uma aplicação pode ser submetida ao Escritório Alemão de Marcas e Patentes (DPMA) como autoridade de transmissão. O DPMA submete então o pedido à Organização Mundial da Propriedade Intelectual (WIPO), que controla o processo internacional mais amplo. $\mathrm{Na}$ fase internacional, que começa com o pedido, uma das autoridades de busca internacional elabora o relatório de busca que é enviado ao solicitante. $\mathrm{O}$ requerente pode então solicitar um exame provisório e, assim, obter uma primeira impressão da proteção de sua invenção (HOFFMAN e RICHTER, 2008).

No máximo após 30 meses da data de prioridade, o declarante deve iniciar, separadamente, a fase nacional (ou regional) antes de cada Escritório designado. Esse é o momento para a escolha dos países signatários para a proteção da patente. Uma opção geralmente escolhida pelos candidatos é a designação da região coberta pelo EPC em uma 
aplicação PCT. Este caminho também pode ser seguido após uma aplicação nacional dentro da prioridade de 12 meses (HOFFMAN e RICHTER, 2008).

$\mathrm{Na}$ Europa, após décadas de negociações entre os estados-membros da União Europeia, em 2012 foi proposta a criação de uma patente única em um Tribunal Europeu de Patentes. Porém, para que a patente única se torne realidade na União Europeia, a Convenção sobre o Tribunal Europeu de Patentes deverá ser ratificada, ao menos por 13 países membros, dentre eles Alemanha, França e Reino Unido (HOFFMAN e RICHTER, 2008).

\section{A propriedade intelectual como fator de desenvolvimento econômico na Alemanha}

Em 1945 a Alemanha se livrou do regime nazista, mas passou a ser controlada pelos aliados, americanos e britânicos. No entanto, tanto Francklin Roosevelt, quanto Winston Churchill não sabiam o que fazer com um país cuja economia estava fundada na produção de armamento bélico, localizados no vale do Ruhr e do Sarre. A proposta inicial, em comum acordo, foi materializada no Plano Morgenthau, cujo objetivo era transformar a Alemanha em um país agrícola. Entretanto, logo esse plano foi descartado, devido às dificuldades na transição de uma cultura bélica altamente industrializada para um agrícola (STIMSON e BUNDY, 1948).

Segundo os autores, a economia alemã continuou apresentando baixos indicadores (em torno de 60\% daqueles apresentados até os anos de 1936), o que resultou em uma grave crise política, pois uma parte do país ainda estava presa aos ideais soviéticos e, a outra aos ideais americanos e britânicos. Dessa insatisfação emergiu o movimento separatista que culminou com a divisão da Alemanha em Ocidental e Oriental. Mas, o que prevaleceu foi o ideal liberalista encadeado por Ludwig Erhard, nomeado Direito da Administração Econômica Bizonal. Em 1948 ele lançou um plano de restauração da economia que aboliu as amarras econômicas do Estado, o que resultou em um aquecimento econômica que resultou em sucesso absoluto dos indicadores no ano seguinte. Em 1949, o índice de produção foi de $143 \%$ em relação a 1948. Foi o início da recuperação da economia Alemã.

Nesse período, ainda não existiam os indicadores de patentes, que somente começaram a existir a partir de 2007, com a divulgação dos indicadores da WIPO. Entretanto, devido a esse 
cenário, fica claro que a transição entre o conhecimento bélico e o conhecimento industrial em outras áreas, certamente, contribuiu para a consolidação do conhecimento doméstico da Alemanha na atualidade, principalmente após a reunificação do País em 03 de outubro de 1990.

Os reflexos de todo esse conhecimento da nação alemã podem ser percebidos nos atuais indicadores econômicos do País (Quadro 2).

Ao analisar-se o desempenho da Alemanha no período de 2007 a 2016, os números demonstram que a propriedade intelectual, notadamente as patentes têm relação direta com o PIB (Quadro 2).

Quadro 2. Relação entre patente, marca e desenho industrial e o PIB da Alemanha, no período de 2007 a 2016

\begin{tabular}{|r|r|r|r|r|}
\hline \multicolumn{5}{|c|}{ PL $($ DOMÉSTICA + EXTERNA, INCLUINDO REGIONAL) E ECONOMIA } \\
\hline ANO & Patente & Marca & Desenho & PIB (Constante 2011 US\$) \\
\hline 2007 & 163,779 & $1,800,775$ & 561,169 & $3,329.61$ \\
2008 & 171,835 & $1,806,827$ & 586,673 & $3,365.65$ \\
2009 & 162,332 & $1,745,954$ & 530,833 & $3,176.54$ \\
2010 & 173,619 & $1,999,020$ & 556,584 & $3,306.14$ \\
2011 & 175,606 & $2,105,613$ & 564,082 & $3,427.14$ \\
2012 & 183,048 & $2,124,688$ & 618,289 & $3,444.00$ \\
2013 & 184,493 & $2,193,102$ & 621,807 & $3,460.86$ \\
2014 & 179,506 & $2,103,796$ & 648,210 & $3,516.08$ \\
2015 & 175,423 & $2,274,047$ & 573,271 & $3,576.58$ \\
2016 & 177,073 & $2,300,068$ & 636,395 & $3,643.36$ \\
\hline
\end{tabular}

O país, apresentando, assim, crescimento linear do número de patentes, o que também foi constatado em relação ao crescimento do PIB (Figura 2). 


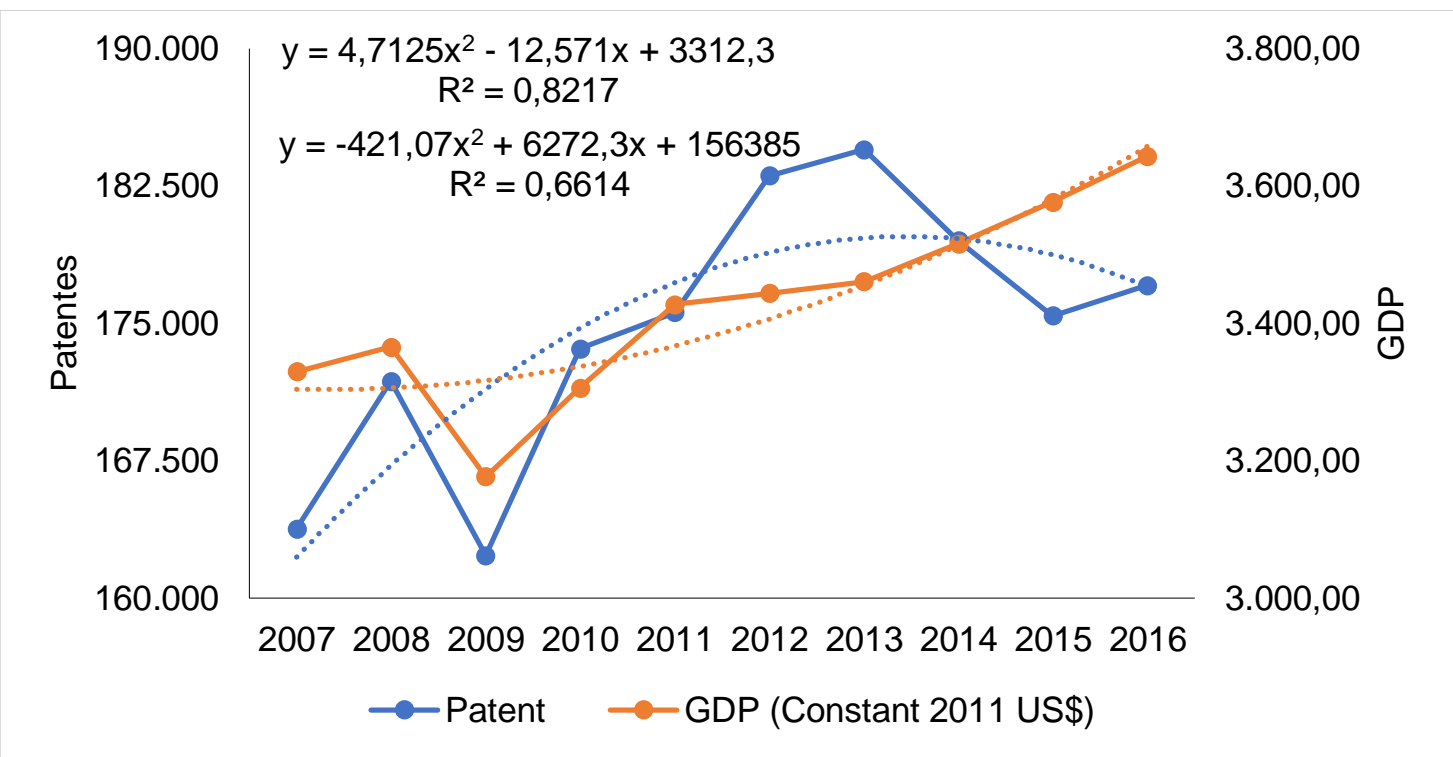

Figura 2. Evolução do número de patentes e crescimento do PIB da Alemanha. no período de 2007-2016. Fonte: Elaborado pelo autor, com base em WIPO (2016).

Ao comparar-se os indicadores da Alemanha (Quadro 2, Figura 2), com outro país desenvolvido, como a Inglaterra, constata-se que essa tendência também se repete (Quadro 3, Figura 3).

Quadro 3. Relação entre patente, marca e desenho industrial, em milhares, e o PIB da Inglaterra, em milhões, no período de 2007 a 2016

\begin{tabular}{|r|r|r|r|r|}
\hline \multicolumn{5}{|c|}{ PL (DOMÉSTICA + EXTERNA, INCLUINDO REGIONAL) E ECONOMIA } \\
\hline ANO & Patente & Marca & Desenho & PIB (Constante 2011 US\$) \\
\hline 2007 & 50.081 & 917.757 & & 2.344 .73 \\
2008 & 51.313 & 855.934 & & 2.330 .03 \\
2009 & 48.709 & & & 2.229 .19 \\
2010 & 50.879 & 899.680 & & 2.271 .88 \\
2011 & 50.805 & 982.807 & 150.775 & 2.306 .17 \\
2012 & 51.562 & 1.095 .148 & 148.541 & 2.336 .45 \\
2013 & 51.300 & 1.173 .889 & 170.282 & 2.381 .10 \\
2014 & 52.605 & 1.274 .123 & 175.859 & 2.454 .21 \\
2015 & 53.393 & 1.343 .701 & 186.201 & 2.508 .06 \\
2016 & 52.909 & 1.223 .673 & 186.905 & 2.553 .36 \\
\hline
\end{tabular}

Fonte: WIPO (2016). 


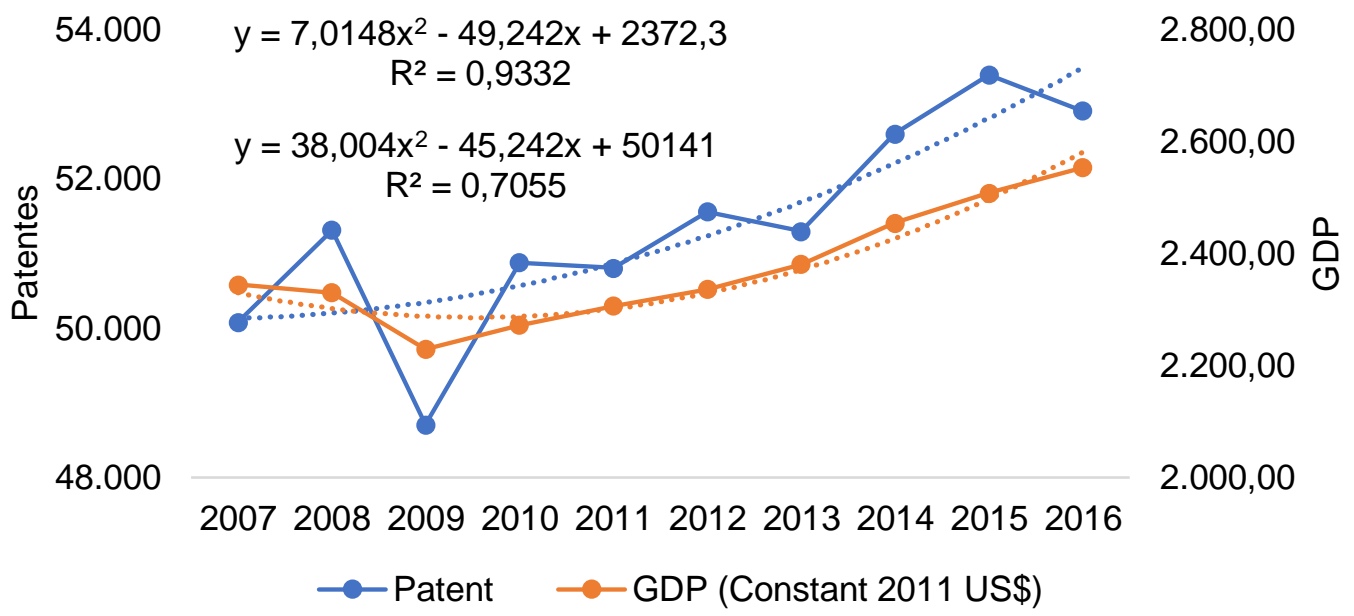

Figura 3. Evolução do número de patentes e crescimento do PIB da Inglaterra, no período de 2007-2016. Fonte: Elaborado pelo autor, com base em WIPO (2016).

$\mathrm{Na}$ Inglaterra, conforme o número de patentes foi aumentando esse reflexo positivo também foi percebido no crescimento do PIB (Quadro 3, Figura 3).

Quadro 4. Aplicações das patentes domésticas (resident), externas (non-resident) e, exportadas (abroad), em milhares, da Alemanha no período de 2007 a 2016

\begin{tabular}{|cccccc|}
\hline Ano & & Doméstica & Estrangeira & Externa \\
\cline { 1 - 2 } \cline { 4 - 5 } \cline { 4 - 5 } & 73.036 & 75.900 & 13.139 & 90.743 \\
& 2008 & 72.971 & 13.177 & 95.935 \\
& 2009 & 74.401 & 11.724 & 89.361 \\
2010 & 73.216 & 12.198 & 99.218 \\
2011 & 73.905 & 12.458 & 102.390 \\
2012 & 73.929 & 14.720 & 109.143 \\
2013 & 73.826 & 15.814 & 110.564 \\
2014 & 72.217 & 17.811 & 105.680 \\
2015 & 73.574 & 19.509 & 103.206 \\
2016 & \multicolumn{2}{c}{ Fonte: WIPO (2016). } \\
\hline
\end{tabular}

Em relação ao spillover de conhecimento, a Alemanha apresentou indicadores similares à Holanda e Inglaterra, ambos países desenvolvidos (Quadros 4, 5 e 6, fígura 4). 


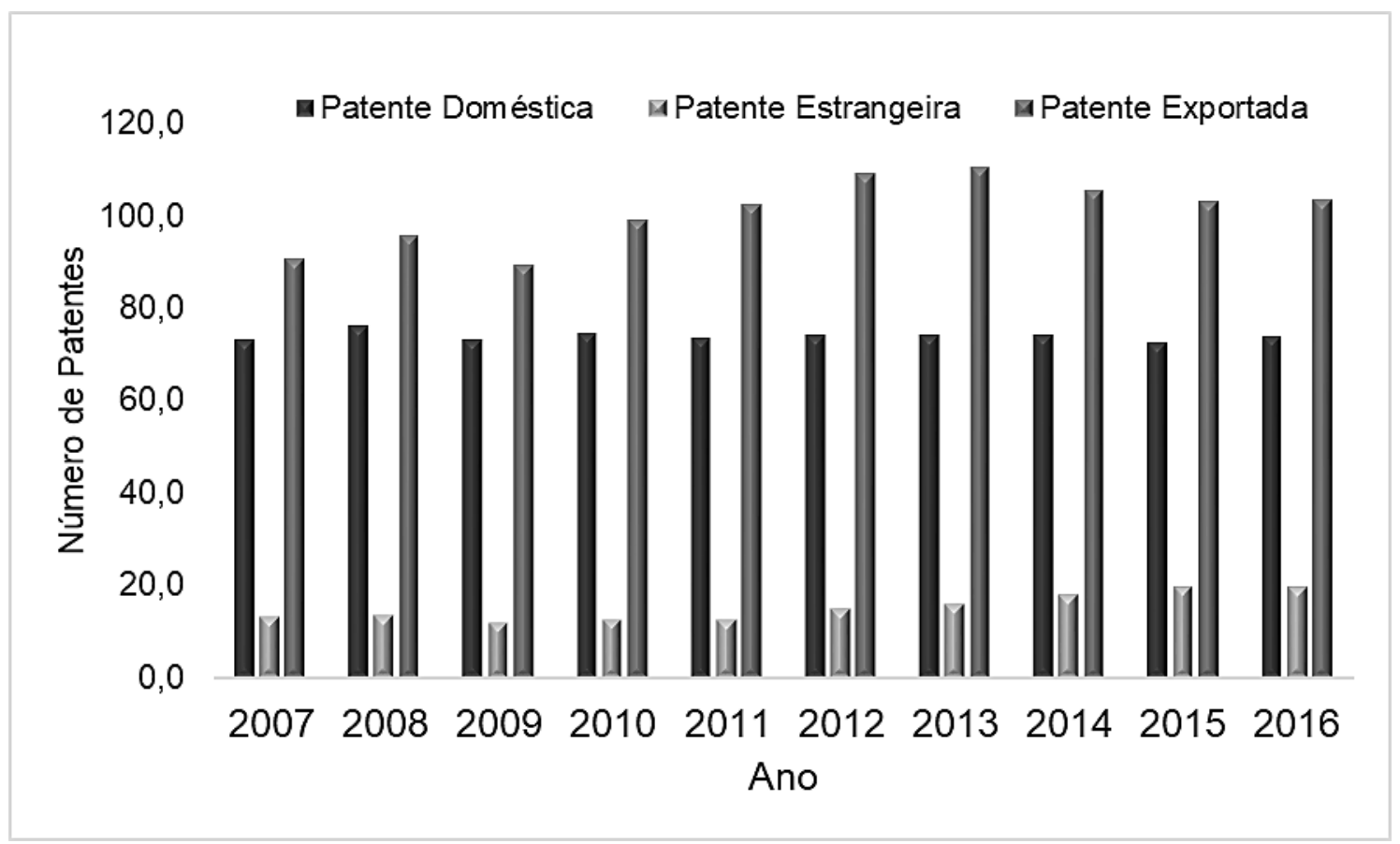

Figura 4. Número de patentes domésticas (resident), estrangeiras (non-resident) e concedidas no exterior (abroad), em milhares, pela Alemanha, no período de 2007 a 2016.

Fonte: Adaptado de WIPO (2016).

Ao se comparar com a Holanda e a Inglaterra, houve comportamento similar de constante spillover de conhecimento em todos os anos do período estudado (Quadros 5 e 6, figuras 5 e 6$)$.

Quadro 5. Aplicações das patentes domésticas (resident), externas (non-resident) e, exportadas (abroad) da Holanda, em milhares, no período de 2007 a 2016

\begin{tabular}{|cccccc|}
\hline Ano & Doméstica & Estrangeira & Externa \\
\cline { 1 - 2 } \cline { 4 - 5 } & 9.079 & 367 & 27.059 \\
2007 & 9.712 & 311 & 27.405 \\
2009 & 9.316 & 279 & 25.259 \\
2010 & 8.484 & 240 & 24.921 \\
2011 & 8.195 & 310 & 25.333 \\
2012 & 7.443 & 338 & 23.862 \\
2013 & 8.151 & 449 & 25.438 \\
2014 & 9.150 & 288 & 28.579 \\
2015 & 9.299 & 287 & 28.842 \\
2016 & 9.128 & 314 & 29.930 \\
\hline
\end{tabular}

Fonte: WIPO (2016). 




Figura 5. Número de patentes domésticas (resident). estrangeiras (non-resident) e concedidas no exterior (abroad). pela Holanda. no período de 2007 a 2016.

Fonte: Adaptado de WIPO (2016).

Diferentemente da Holanda, a Alemanha e Inglaterra, embora apresentem uma superioridade de indicadores em relação às patentes domésticas e spillover de conhecimento, ainda apresentam números significativos de patentes externas (Quadros 4 e 6, Figuras 4 e 6).

Quadro 6. Aplicações das patentes domésticas (resident), externas (non-resident) e, exportadas (abroad), em milhares, da Inglaterra, no período de 2007 a 2016

\begin{tabular}{|c|c|c|c|}
\hline Ano & Doméstica & Estrangeira & Externa \\
\hline 2007 & 22.356 & 7.624 & 27.725 \\
\hline 2008 & 21.593 & 6.856 & 29.720 \\
\hline 2009 & 20.807 & 6.480 & 27.902 \\
\hline 2010 & 20.892 & 6.439 & 29.987 \\
\hline 2011 & 20.107 & 6.916 & 30.698 \\
\hline 2012 & 20.108 & 7.865 & 31.454 \\
\hline 2013 & 19.552 & 7.966 & 31.748 \\
\hline 2014 & 19.922 & 7.844 & 32.683 \\
\hline 2015 & 19.904 & 7.934 & 33.489 \\
\hline 2016 & 19.009 & 8.183 & 33.900 \\
\hline
\end{tabular}

Fonte: WIPO (2016). 
Os números da Inglaterra impressionam, como podemos observar na Figura 6, em que os indicadores de exportação de conhecimento superam, inclusive, os indicadores de conhecimento nacional, demonstrando assim sua imensa capacidade de produzir riquezas.



Figura 6. Número de patentes domésticas (resident), estrangeiras (non-resident) e concedidas no exterior (abroad), em milhares, pela Inglaterra, no período de 2007 a 2016.

Fonte: Adaptado de WIPO (2016).

Percebe-se com isto que a Alemanha, em relação à Holanda e Inglaterra, igualmente desenvolvidos, se sobressai por ter privilegiado a patente doméstica, mesmo estando todos sob o mesmo regime de proteção, que é o Tratado da União Europeia. O diferencial da proteção jurídica da Alemanha foi, basicamente, a sua tradição no reconhecimento do vínculo entre autor e obra no seu mais amplo aspecto, não somente para os direitos de autor, mas, também em relação ao conhecimento científico em geral. Percebe-se essa preocupação, quando o País protege o vínculo eterno entre o autor e seu conhecimento, como direito fundamental e não apenas como direito econômico. Essa preocupação alemã proporcionou a proteção de seu conhecimento mundo afora, o que prevalece até os dias atuais, mesmo estando sob novos acordos multilaterais, como os ditados pela OMC. 


\section{CONCLUSÃO}

Ao proteger o vínculo entre autor e obra, os alemães protegeram o esforço do autor para construir a obra e consequentemente, proporcionaram ambiente favorável ao desenvolvimento econômico do país.

O entendimento de esforço está solidificado em três pilares: trabalho, tempo e dinheiro. Unindo esses três elementos, é necessário que a propriedade intelectual de um bem, seja ele tangível ou intangível. Deste modo, o Sistema Jurídico Alemão compreendeu que protegendo o esforço de um cidadão, consequentemente estará protegendo sua dignidade humana, base angular dos direitos fundamentais.

Os resultados desse Sistema de Proteção do Conhecimento consolidaram o desenvolvimento para toda a nação alemã e a prova de que trilhou corretamente o caminho da propriedade intelectual está em seus indicadores. O país detém um dos maiores PIB's do mundo, em conjunto com os melhores indicadores de spillover de conhecimento.

\section{REFERÊNCIAS BIBLIOGRÁFICAS}

BRASIL. Código Civil e Normas Correlatas. 6ed. Brasília: Senado Federal, Coordenação de Edições Técnicas, 2016b. 372p.

BRASIL. Constituição da República Federativa do Brasil. Brasília: Senado Federal, Coordenação de Edições Técnicas, 2016a. 123p.

BRASIL. Decreto $\mathrm{n}^{\circ} 1.355$, de 30 de dezembro de 1994. Promulga a Ata Final que incorpora os Resultados da Rodada Uruguai de Negociações Comerciais Multilaterais do GATT. Diário Oficial (da) República Federativa do Brasil, Poder Executivo, Brasília, DF, Seção I, p. 21.394, em 31 dezembro 1994.

BRASIL. Lei do Direito Autoral. 2ed. Brasília: Senado Federal, 2004. 107p.

BRASIL. Lei $n^{\circ}$ 9.279, de 14 de maio de 1996. Regula direitos e obrigações relativos à propriedade industrial. Publicada no Diário Oficial (da) República Federativa do Brasil, Poder Executivo, Brasília, DF, 14 mai. 1996. 
BRASIL. Lei $\mathrm{n}^{\circ}$ 9.609, de 19 de fevereiro de 1998, regula os direitos de propriedade intelectual sobre programas de computador. Publicada no Diário Oficial (da) República Federativa do Brasil, Poder Executivo, Brasília, DF, 20 fev. 1998.

BRASIL. Lei $\mathrm{n}^{\circ}$ 12.529, de 30 de novembro de 2011, que estrutura o Sistema Brasileiro de Defesa da Concorrência e dispõe sobre a prevenção e repressão às infrações contra a ordem econômica. Publicada no Diário Oficial (da) República Federativa do Brasil, Poder Executivo, Brasília, DF, $1^{\circ}$ nov. 2011.

BUSKOP, W. Patents, Trademarks, Copyrights, and Trade Secrets: What Automation Professionals, Manufacturers, and Business Owners Need to Know. 1ed. Research Triangle Park: ISA, 2008. 134p.

CAVAliERI FILHO, S. Programa de Responsabilidade Civil. 11ed. São Paulo: Atlas, 2015. 672p.

CLARK, M.; OXMAN, A. Cochrane Reviewers Handbook. Oxford: The Cochrane Library, 2001. 672p.

DEUTSCHLAND. Deutsche Bundesverfassung. Bonn: Bundesministeriums der Justiz, 1949, 50p. Bonn, 1949. [online]. Disponível em: 〈https://www.gesetze-im-internet.de/gg/GG.pdf〉. Acesso em: 14 dez. 2017.

GAGLIANO, P.; PAMPLONA FILHO, R. Novo Curso de Direito Civil: Direito das sucessões. 4ed. São Paulo: Saraiva, 2014. v. 7. 480p.

HOFFMANN, M.; RICHTER T. Geistiges Eigentum in der Betriebspraxis: Erlangung, Verwaltung, Verteidigung und Verwertung von Patenten, Marken, Designs und Copyrights im Unternehmen. 2ed. Berlin: Springer Gabler, 2008. 345p.

KUR, A.; DREIER, T. European Intellectual Property Law: Text, Cases and Materials. Massachusetts: Edward Elgar Pub, 2012. 592p.

SILVA, L. C. S. Modelo de Transferência de Tecnologia Verde por Intermédio dos Núcleos de Inovação Tecnológica em Institutos de Ciência e Tecnologia Brasileiros. 2016. 146f. Tese (Doutorado em Engenharia de Produção) - Escola de Engenharia, Universidade Federal do Rio Grande do Sul, Porto Alegre.

STIMSON, H. L.; BUNDY, M. On Active Service in Peace and War. New York: Harper \& Bros., 1948, 581p.

TRANFIELD, D.; DENYER, D.; SMART, P. Towards a Methodology for Developing Evidence-Informed Management Knowledge by Means of Systematic Review. British Journal of Management, London, v. 14, n. 3, p. 207-222, 2003. 
VENOSA, S. S. Direito Civil: Teoria Geral das Obrigações e Teoria Geral dos Contratos. 11ed. São Paulo: Atlas, 2011. v. II. 631p.

WIPO. World Intellectual Property Organization. Statistical Country Profiles. Geneva, 2016. [online]. Disponível em: <http://www.wipo.int/ipstats/en/statistics/country_profile/profile.jsp?code=DE>. Acesso em: 07 nov. 2017.

WIPO. World Intellectual Property Organization. Agreement on Trade-Related Aspects of Intellectual Property Rights (TRIPS). Genebra, 2017. [online]. Disponível em: <http://www.wipo.int/tools/en/gsearch.html?cx=016458537594905406506\%3Ahmturfwvzzq \&cof=FORID\%3A11\&q=trips>. Acesso em: 08 nov. 2017.

WIPO. World Intellectual Property Organization Patent Cooperation Treaty. Geneva, 2018. [online]. <http://www.wipo.int/export/sites/www/treaties/en/documents/pdf/pct.pdf $>$. Acesso em: 16 mai. 2018.

Submetido em: 03/05/2019

Aceito em: 05/09/2019 